\title{
Tiny fibrovascular polyps of the esophagus as incidental findings - look carefully or you might miss them
}

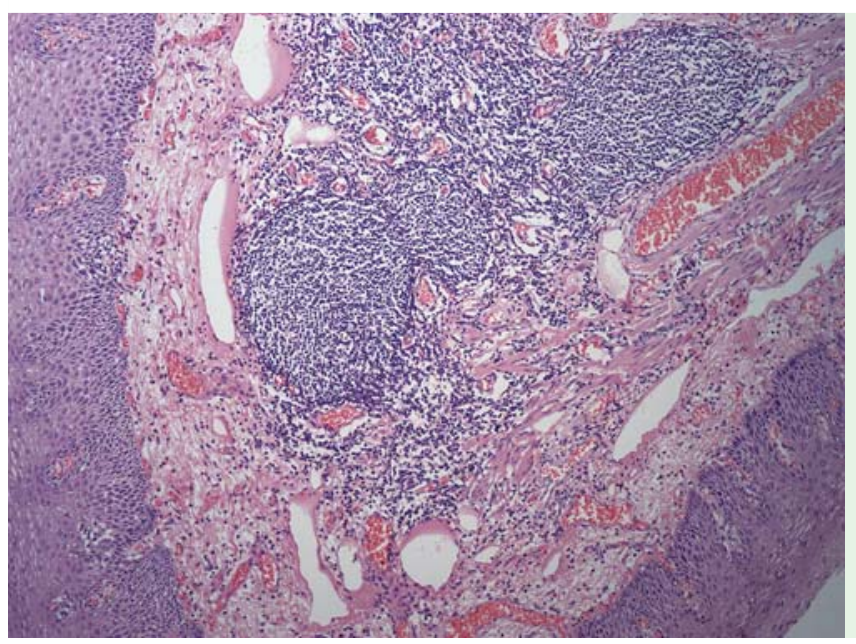

Fig. 1 Histopathological features of a fibrovascular polyp.

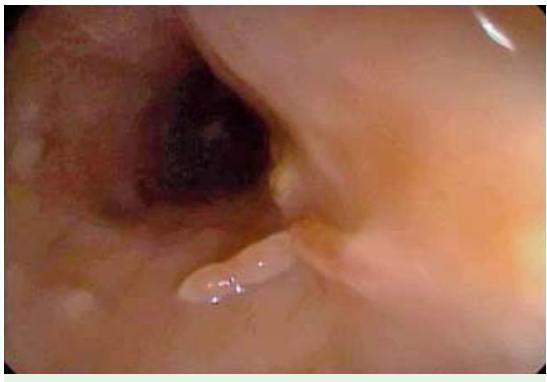

Fig. 2 Case of fibrovascular polyp of the esophagus with two polyps.

Fibrovascular polyps of the esophagus are rare benign lesions that arise from the cervical esophagus. Most of them are only diagnosed when their size induces symptoms [1].

Five asymptomatic patients (four women, age range: 26-49 years) were found to have esophageal tumors on endoscopy. Histological examination revealed polypoid lesions $(0.2-0.8 \mathrm{~cm})$ with vascularized loose fibrous shafts, lined by stratified squamous epithelium with preserved maturation, compatible with fibrovascular polyp of the esophagus ( Fig. 1). All the polyps were solitary, except in one patient who had two polyps ( $\mathbf{F i g}$. 2). This patient, who had multiple sclerosis, also had a raised $0.5-\mathrm{cm}$ lesion covered by normal mucosa, with central umbilication, in the greater curvature of the antrum, compatible with ectopic pancreas. We removed all the polyps endoscopically using standard forceps ( $\bullet$ Fig. 3).

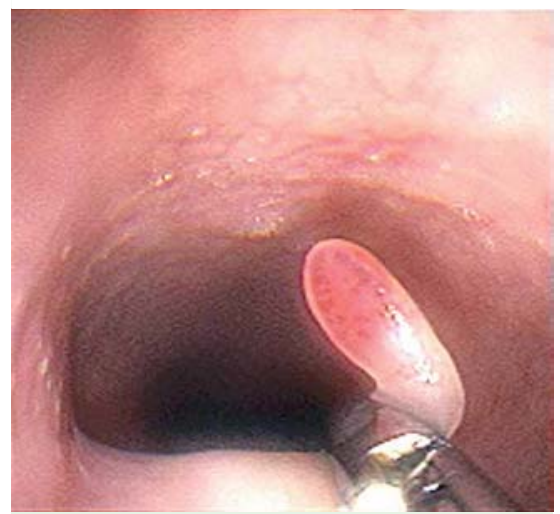

Fig. 3 Endoscopic resection of a fibrovascular polyp of the esophagus with standard forceps.

Fibrovascular polyps of the esophagus are benign tumors composed of fibroadipose tissue and blood vessels and lined by normal squamous epithelium [1,2]. Almost all fibrovascular polyps of the esophagus arise from the segment just inferior to the cricopharyngeus muscle $[3,4]$. They are very rare, representing less than $2 \%$ of all benign esophageal tumors [1]. Of the few more than 100 cases reported in the world literature to date, most were only diagnosed when their size induced symptoms, especially dysphagia [1]. Although fibrovascular polyps of the esophagus tend to be solitary, [3] one of our patients had two polyps. Furthermore, to the best of our knowledge, this is the first report of fibrovascular polyps of the esophagus associated with both ectopic pancreas and multiple sclerosis. The most important point of this report is to emphasize awareness of this diagnosis. Although rare, fibrovascular polyps of the esophagus are the most common benign intraluminal lesions of the esophagus and can be missed on endoscopy. Diagnosing fibrovascular polyps of the esophagus requires knowledge of their appearance and careful scrutiny of the upper esophageal region.

Endoscopy_UCTN_Code_CCL_1AB_2AC_3AB

Competing interests: None

\author{
L. Lenz ${ }^{1,2}$, G. Luz ${ }^{1,3}$, A. Felipe-Silva ${ }^{1,4}$, \\ F. Nakao ${ }^{1,2}$, E. Libera ${ }^{1,2}$, D. Chaves ${ }^{1,3}$, \\ B. Sugai ${ }^{1,3}$, R. Rohr ${ }^{1,2}$ \\ 1 Fleury Medicina e Saúde, São Paulo, Brazil \\ 2 Universidade Federal de São Paulo, \\ São Paulo, Brazil \\ 3 Universidade de São Paulo, São Paulo, \\ Brazil \\ ${ }^{4}$ Hospital Universitário, Serviço de Anato- \\ mia Patológica, São Paulo, Brazil
}

\section{References}

1 Drenth J, Wobbes T, Bonenkamp JJ et al. Recurrent esophageal fibrovascular polyps: case history and review of the literature. Dig Dis Sci 2002; 47: 2598-2604

2 Levine MS, BuckJL, Pantongrag-Brown L et al. Fibrovascular polyps of the esophagus: clinical, radiographic, and pathologic findings in 16 patients. AJR Am J Roentgenol 1996; 166: $781-787$

3 Been MJ, Hinsely ML, Hartig GK. Fibrovascular polyp of the cervical esophagus. Am J Otolaryngol 2009; 30: 134-136

4 Luthen $R$, Janzik $U$, Derichs $R$ et al. Giant fibrovascular polyp of the esophagus. Eur J Gastroenterol Hepatol 2006; 18: $1005-$ 1009

\section{Bibliography}

DOI $10.1055 / \mathrm{s}-0030-1256933$

Endoscopy 2011; 43: E392

(c) Georg Thieme Verlag KG Stuttgart · New York . ISSN 0013-726X

\section{Corresponding author}

\section{Lenz}

Fleury Medicina e Saúde

Avenida Aratãs

200 Apto 121 B

São Paulo

Brazil 04081-000

Fax: +55-11-5576405

luciano.lenz@terra.com.br

luciano.tolentino@fleury.com.br 